\title{
28 Research Square \\ Preparation of green synthesized copper oxide nanoparticles for efficient removal of lead from wastewaters
}

\section{Amir Zarrabi}

Shiraz University School of Agriculture

Reza Ghasemi-Fasaei ( $\nabla$ ghasemif@shirazu.ac.ir )

Shiraz University School of Agriculture https://orcid.org/0000-0003-4410-4963

\section{Research}

Keywords: Adsorption, copper oxide, green synthesis, lead, nanoparticles, removal efficiency

Posted Date: March 8th, 2021

DOl: https://doi.org/10.21203/rs.3.rs-286270/v1

License: (c) (1) This work is licensed under a Creative Commons Attribution 4.0 International License.

Read Full License 


\section{Abstract}

Green synthesis is a clean and eco-friendly process in which metal nanoparticles can be produced via reaction between a metal salt solution and plant organ extract. In present study, three copper oxide nanoparticles were synthesized using green synthesis processes from the leaf extracts of selected plants as abundant plant cover in the study area including astragalus (Astragalus membranaceus), rosemary (Salvia rosmarinus) and mallow (Malva sylvestris). The effectiveness of three green synthesized nanoparticles in the adsorption of lead ions from a polluted water was studied under laboratory conditions. According to the results, the removal efficiencies of the copper oxide nanoparticles synthesized from astragalus (A-CuO-NPs), rosemary (R-CuO-NPs) and mallow leaf extract (M-CuO-NPs) especially at the highest initial concentration of $\mathrm{Pb}(1.5 \mathrm{mM})$ were $88.4 \%, 84.9 \%$ and $69.6 \%$, respectively. Most probably due the smooth morphology and more uniform configuration of the M-CuO-NPs, the changes between equilibrium adsorption $\left(q_{e}\right)$ and equilibrium concentration $\left(C_{e}\right)$ were more regular than those of the A-CuO-NPs and R-CuO-NPs. Accordingly the best fitted data to Langmuir and Freundlich isotherms were observed in the adsorption of $\mathrm{Pb}$ onto the M-CuO-NPs. Despite the lowest removal efficiency of the M-CuO-NPs, with the equal volumes of each leaf extract and $\mathrm{CuSO}_{4} \cdot 5 \mathrm{H}_{2} \mathrm{O}$ solution (20 $\mathrm{mM}$ ), the most produced dry weight was observed for these nanoparticles (4.3 g per $100 \mathrm{~mL}$ of leaf extract). According to the results reported herein, the copper oxide nanoparticles synthesized from different plant covers are efficient adsorption agents for $\mathrm{Pb}$ from wastewaters.

\section{Introduction}

Nowadays with increasing industrialization of the world, petroleum sectors and sewage landfills are as important factors that cause water pollution by heavy metals [1]. Lead $(\mathrm{Pb})$ is a highly hazardous metal and its wide distribution in polluted waters is a serious concern for environmental health experts. Low concentrations of $\mathrm{Pb}$ have negative effects on kidney, liver and brain [2]. The allowable levels of $\mathrm{Pb}$ in drinking water are 15 and $50 \mathrm{\mu g} \mathrm{L}^{-1}$ determined by Environmental Protection Agency (EPA) and the World Health Organization (WHO), respectively [3]. Pb cations are commonly present in wastewaters issuing from the factories producing plastic, paint, pulp, paper, battery and etc [4]. The concentration of $\mathrm{Pb}$ in the wastewaters may be ranged from 200 to $500 \mathrm{mg} \mathrm{L}^{-1}$ as reported by Arbabi et al. [5]. Therefore reduction of $\mathrm{Pb}$ concentration in the wastewaters before releasing into aquatic and land systems should be under serious consideration [6]. Several approaches have been carried out for $\mathrm{Pb}$ removal from aqueous solutions such as reduction [7], ion exchange [8], precipitation [9] membrane separation [10]. Another method is sorption which is the most common due to its low cost, availability of materials, having no environmental effects and etc [11]. Development in nanotechnology have been provided nanoparticles including nanotubes, nanowires and metal nanoparticles [12]. Remarkable properties such as high specific area and strong metal sorption capacity are the main reasons for the application of metal oxide nanoparticles in order to remove heavy metal ions from polluted waters [13]. Due to the vast demands for copper oxide nanoparticles in various domains of research and industry, there are several procedures to synthesize these compounds including thermal or chemical reduction, wire explosion and laser erasing 
[14]. The size and purity of the produced nano copper oxides are different based on the production technique. Some of the mentioned techniques for example thermal processes require reducing agents such as hydrazine which has serious negative impact on the environment [15]. Green synthesis method is an eco-friendly and low cost approach for the synthesis of metal oxide nanoparticles using organisms. Among the organisms, plants are the best selection because they are more suitable for large scale and fast rate production of metal nanoparticles. In this method active functional groups in leaf extract of a selected plant act as reducing agents of metal ions [16]. Many researchers have studied the biosynthesis of metal oxide nanoparticles: Menon et al. [17] used the seeds of $M$. pureins and sodium selenite for the production of selenium nanoparticles and evaluating its antimicrobial activities. Copper oxide nanoparticles with a size range of $45-100 \mathrm{~nm}$ were produced by Kuppusamy et al. [18] using Commelina nudiflora leaf extract for the control of microbial growth in a palm oil mill effluent. Sankar et al. [19] studied the photocatalytic degradation of an organic dye Coomassie in confronting with copper oxide nanoparticles synthesized by Carica papaya leaf extract. It is hypothesized that copper oxide nanoparticles synthesized from different plant extracts, have different metal adsorption capacities. Therefor the main objectives of the present study were (i) to prepare copper oxide nanoparticles from the leaf extracts of three plants as predominant plant cover in our study area through green synthesis approach and (ii) to characterize the synthesized nanoparticles and investigate the effectiveness of the three synthesized nanoparticles for the removal of lead ions from a polluted water.

\section{Materials And Methods}

\section{Green synthesis of $\mathrm{CuO}$ nanoparticles}

Green synthesis process was performed according to the method proposed by Sankar et al. [19]. Three plants (Fig 1): mallow (Malva sylvestris), and astragalus (Astragalus membranaceus) as self-growing and predominant plant covers and rosemary (Salvia rosmarinus) as vastly cultivated plant in Iran, Fars, Shiraz, Bajgah, were collected.

Plants leaves were separated and washed thoroughly with deionized water then dried in an oven at $50{ }^{\circ} \mathrm{C}$ until complete drying. The dried plant leaves were powdered and $10 \mathrm{~g}$ of each sample were added to 100 $\mathrm{mL}$ deionized water and heated at $60^{\circ} \mathrm{C}$ for an hour to obtain the plant leaf extracts. The extracts were filtered using Whatman No. 42 then stored in refrigerator for next steps. $10 \mathrm{~mL}$ of each filtered extract was mixed with $90 \mathrm{~mL}$ of cupric sulphate $\left(\mathrm{CuSO}_{4} \cdot 5 \mathrm{H}_{2} \mathrm{O}\right)$ solution $(20 \mathrm{Mm})$ and kept for 24 hours to complete change in the color of the solution in comparison with the initial solution as an indicator for forming the suspensions of copper oxide nanoparticles. Copper oxide nanoparticles were prepared as dry matter following the evaporation of suspensions' liquid at $50{ }^{\circ} \mathrm{C}$. The dry weight obtained (g per $100 \mathrm{~mL}$ ) from each leaf extract was reported as dry matter yield.

Characterization of the synthesized copper oxide nanoparticles 
Functional groups of the synthesized copper oxide nanoparticles were characterized using Fouriertransform infrared spectroscopy (FTIR) (Bruker Tensor II, Germany). The morphology of the produced copper oxide nanoparticles was recognized by scanning electron microscope (SEM), TESCAN-Vega 3. Xray diffraction analysis was performed using XRD, Philips model: PW1130, Cu Ka radiation, 2 $\triangle=20-70^{\square}$.

Sorption experiments

Equilibrium experiments were performed as follows: the initial concentrations of $0.15,0.3,0.6,1$ and 1.5 $\mathrm{mM}$ of $\mathrm{Pb}$ as an aqueous solution of $\mathrm{Pb}$ nitrate were prepared. $30 \mathrm{~mL}$ from each concentration was added to $0.2 \mathrm{~g}$ of the synthesized copper oxide nanoparticles each in duplicates in separate polyethylene containers and the experiments were carried out at $\mathrm{pH}$ of 7 . The solutions were agitated for $24 \mathrm{~h}$ at $25^{\circ} \mathrm{C}$ at $200 \mathrm{rpm}$ then filtered by Whatman No. 42 [20]. The concentrations of Pb in the filtrates were measured using an atomic adsorption spectrophotometer. The amounts of $\mathrm{Pb}$ adsorbed by copper oxide nanoparticles were calculated by equation 1 :

$\mathrm{q}_{\mathrm{e}}=\left[\left(\mathrm{C}_{0}-\mathrm{C}_{\mathrm{e}}\right) \mathrm{V}\right] / \mathrm{W}$

Removal efficiency (RE) of metal (\%) was determined by equation 2 :

$R E=\left[\left(C_{0}-C_{e}\right) / C_{0}\right] \times 100$

Distribution coefficient, $\mathrm{K}_{\mathrm{d}}\left(\mathrm{L} \mathrm{g}^{-1}\right)$ was calculated using equation

3:

$\mathrm{K}_{\mathrm{d}}=$ (mass of adsorbate sorbed / mass of adsorbate in solution)

sorption of $\mathrm{Pb}$ cations onto nanoparticles was modelled using linear sorption isotherms of Langmuir, type II (4) and Freundlich (5) according to Hamzaoui et al. [21]:

$1 / q_{e}=1 / C_{e} k_{L} b+1 / b$

$\ln \mathrm{q}_{\mathrm{e}}=1 / \mathrm{n}\left(\ln \mathrm{C}_{\mathrm{e}}\right)+\ln \mathrm{k}_{\mathrm{F}}$

Gibb's free energy $\left(\Delta \mathrm{G} \mathrm{kJmol}{ }^{-1}\right)$ was evaluated using equation 6 and 7 [22]:

$k_{e}=q_{e} / C_{e}$

The van't Hoff equation:

$\Delta \mathrm{G}=-\mathrm{RT} \ln \mathrm{k}_{\mathrm{e}}$

where $\mathrm{q}_{\mathrm{e}}$ is the metal adsorbed onto copper oxide nanoparticles at equilibrium ( $\mathrm{mg} \mathrm{g}^{-1}$ ), $\mathrm{C}_{0}$ and $\mathrm{C}_{\mathrm{e}}$ are initial and equilibrium concentrations of $\mathrm{Pb}$ in solution $\left(\mathrm{mg} \mathrm{L}^{-1}\right)$, respectively. $\mathrm{V}$ is the volume of solution 
$(\mathrm{mL})$, and $\mathrm{W}$ is the mass of nanoparticles $(\mathrm{g}) \cdot \mathrm{k}_{\mathrm{L}}$ is the Langmuir constant $\left(\mathrm{L} \mathrm{mg}^{-1}\right), \mathrm{b}$ is monolayer sorption capacity with metal ions $\left(\mathrm{mg} \mathrm{g}^{-1}\right)$, $\mathrm{n}$ is sorption intensity, $\mathrm{k}_{\mathrm{F}}\left(\mathrm{mg} \mathrm{g}^{-1}\left(\mathrm{~L} \mathrm{mg}^{-1}\right)^{1 / n}\right)$ is the sorption capacity of the adsorbent, $\mathrm{k}_{\mathrm{e}}$ is the thermodynamic equilibrium constant, $\mathrm{R}$ is the gas constant $(8.314$ $\mathrm{Jmol}^{-1} \mathrm{~K}^{-1}$ ) and $\mathrm{T}$ is the absolute temperature $\left({ }^{\circ} \mathrm{K}\right) . \mathrm{q}_{\mathrm{e}}$ and $\mathrm{C}_{\mathrm{e}}$ in equation (7) are in ppm.

\section{Results And Discussion}

Synthesis mechanism

In the green synthesis of copper oxide nanoparticles, the extract of plant organs especially leaves are used as sources of the active functional groups such as carboxylic and phenolic acids. This functional groups act as reducing agents. Following the transfer of a proton from a functional group to $\mathrm{Cu}^{2+}, \mathrm{Cu}^{+}$is formed, and subsequently the transfer of the second proton from other functional group to $\mathrm{Cu}^{+}$, the nanoparticle of $\mathrm{CuO}$ is produced [23].

Characterization of the synthesized copper oxide nanoparticles

According to Fig 2 the FTIR analysis shows strong absorbtions (100 - \% Transmission) in the wave numbers of $435.4,436.4$ and $601.44 \mathrm{~cm}^{-1}$, in the synthesized copper oxide nanoparticles from the leaf extracts of astragalus (A-CuO-NPs), rosemary (R-CuO-NPs) and mallow (M-CuO-NPs) leaf extracts, respectively, which confirm the vibrations of Cu-O bonds [24]. Strong absorbtions between the wave numbers of 1000 to $1300 \mathrm{~cm}^{-1}$ indicate the presence of $\mathrm{C}-\mathrm{O}$ groups (alcohols, ethers, esters, carboxylic acids, anhydrides) and broad peaks in the range of 2400 to $3400 \mathrm{~cm}^{-1}$ are the indicatives of carboxylic acids $(\mathrm{O}-\mathrm{H})$ probably on the surfaces of all three synthesized nanoparticles [25].

SEM micrographs of three nanoparticles were shown in Fig 3. These photos display the agglomerative shapes of the nanoparticles which probably their surfaces and intermediates are filled with other organic compounds that varies depending on plant origin as explained in FTIR analysis. A-CuO-NPs, R-CuO-NPs and M-CuO-NPs represent almost cubic, prismatic and lineolate shapes, respectively. The A-CuO-NPs and R-CuO-NPs have course configurations whereas the appearance of M-CuO-NPs is relatively smooth.

The XRD patterns of the synthesized copper oxide nanoparticles are shown in Fig 4. The most strong peaks were observed at $2 \nabla=31.37 \nabla$ for the A-CuO-NPs, $2 \nabla=28.29 \nabla$ and $25.78 \nabla$ for the R-CuO-NPs and $2 \nabla$ $=28.61 \mathrm{Q}$ for the M-CuO-NPs which indicated the presence of CuO. In other researchs, Kuppusamy et al. [18] found an obvious peak at $2 \bigotimes=24^{\circ}$ for their green synthesized copper oxide nanoparticles. Singh et al. [26] reported that the most intense peak at $2 \mathbb{Z}=31.6^{\circ}$, showed the presence of crystalline $\mathrm{CuO}$ in their biosynthesized copper oxide nanoparticles. 
Following the reactions between the leaf extracts and $\mathrm{CuSO}_{4} \cdot 5 \mathrm{H}_{2} \mathrm{O}$ solution after the adequate time (24 hours), the formation of copper oxide nanoparticles became stable and the suspensions of the nanoparticles were observed in the containers. As is shown in Fig 5, the densest suspension was formed in mallow leaf extract. The nanoparticles synthesized by rosemary leaf extract were finer than that of mallow and the suspended nanoparticles in astargalus leaf extract were clear as very fine points. The dry matter yield of the synthesized copper oxide nanoparticles per $100 \mathrm{~mL}$ of each plant leaf extract were 4.3, 3.05 and $1.81 \mathrm{~g}$ for the M-CuO-NPs, R-CuO-NPs and A-CuO-NPs, respectively. In general, with the same volume of each leaf extract and equal concentrations of $\mathrm{CuSO}_{4} \cdot 5 \mathrm{H}_{2} \mathrm{O}$ solution, the highest dry mass was obtained for the M-CuO-NPs. Larger particles formed in mallow leaf extract can be related to smooth and broad morphology of the M-CuO-NPs. However, finer particles in rosemary and astargalus leaf extracts may be due to the rough configurations in the A-CuO-NPs and R-CuO-NPs (Fig 3).

(Fig 5)

Sorption of $\mathrm{Pb}$ onto the synthesized copper oxide nanoparticles

Maximum values of $\mathrm{q}_{\mathrm{e}}$ were $41.19,39.88$ and $32.44\left(\mathrm{mg} \mathrm{g}^{-1}\right)$ for the A-CuO-NPs, R-CuO-NPs and M-CuONPs, respectively. Higher $\mathrm{q}_{\mathrm{e}}$ values for the A-CuO-NPs and R-CuO-NPs, probably were due to more course configurations in these two nanoparticles in comparison with the M-CuO-NPs. The pattern of changes in $\mathrm{C}_{\mathrm{e}}$ vs $\mathrm{q}_{\mathrm{e}}$ are shown in Fig 6. In the highest concentration of $\mathrm{C}_{0}(1.5 \mathrm{mM})$, the values of $\mathrm{C}_{\mathrm{e}}$ for A-CuO-NPs, R-CuO-NPs and M-CuO-NPs were 0.174, 0.226 and $0.455 \mathrm{mM}\left(36.17,44.93\right.$ and $\left.94.47 \mathrm{mg} \mathrm{L}^{-1}\right)$, respectively. These changes were different in the presence of three studied nanoparticles. In A-CuO-NPs and R-CuO-NPs, $C_{e}$ increased with increasing in $C_{0}$ from 0.15 to $0.6 \mathrm{mM}$ and 0.15 to $1 \mathrm{mM}$, respectively, and decreased afterwards. In M-CuO-NPs, however, $\mathrm{C}_{\mathrm{e}}$ increased constantly with increasing in $\mathrm{C}_{0}$. The changes values in the equilibrium concentrations of $\mathrm{Pb}\left(\mathrm{C}_{\mathrm{e}}\right)$ are given in Table 1. Generally the differences in the changes of $\mathrm{C}_{\mathrm{e}}$ can be attributed to different morphology and removal capacity of three studied nanoparticles.

The most removal efficiencies belonged to the lowest $C_{0}$ for all three nanoparticles $(91.3,89.3$ and $87.3 \%$ for the A-CuO-NPs, R-CuO-NPs and M-CuO-NPs, respectively). The removal efficiencies of the synthesized nanoparticles in the highest concentration of $\mathrm{Pb}(1.5 \mathrm{mM})$ were in the following order: A-CuO-NPs (88.4 $\%)>$ R-CuO-NPs (84.9\%) > M-CuO-NPs (69.6\%). Farghali et al. [13] in their study on four shapes of copper oxide nanoparticles reported the $\mathrm{Pb}$ removal efficiencies between 87 to $100 \%$ in initial concentration of $100 \mathrm{mg} \mathrm{L}^{-1}$ and 78 to $87 \%$ in initial concentration of $300 \mathrm{mg} \mathrm{L}^{-1}$.

Removal of $\mathrm{Pb}$ by other active adsorbents has been studied in previous researches. Daryabeigi Zand and Rabiee Abyaneh [27] reported that the removal of $\mathrm{Pb}$ by a crushed wood-derived biochar $\left(10 \mathrm{~g} \mathrm{~L}^{-1}\right)$ after 1400 min was $60 \%$. Ablouh et al. [28] showed that the maximum adsorption of $\mathrm{Pb}$ from an aqueous solution by a green adsorbent based on chitosan microspheres/sodium alginate hybrid beads was $60 \%$. 
Ibupoto et al. [29] found that $2 \mathrm{mg}$ of $\mathrm{ZnO} /$ Carbon nanofibers caused $80 \%$ removal of $\mathrm{Pb}$ in a $20 \mathrm{ml}$ of 10 ppm lead solution after 80 min.

The mass ratio of $\mathrm{Pb}$ sorbed onto nanoparticle $\left(\mathrm{mg} \mathrm{g}^{-1}\right)$ to $\mathrm{Pb}$ in solution $\left(\mathrm{mg} \mathrm{L}^{-1}\right)$ is defined as distribution coefficient $\left(\mathrm{K}_{d}\right)$. The highest values of $\mathrm{K}_{d}$ were observed in the lowest $\mathrm{C}_{0}$ for all three nanoparticles (1.42, 1.21 and $1 \mathrm{~L} \mathrm{~g}^{-1}$ for the A-CuO-NPs, R-CuO-NPs and M-CuO-NPs, respectively). In the highest initial concentration of $\mathrm{Pb}(1.5 \mathrm{mM})$, the $\mathrm{K}_{d}$ values were in the following order: A-CuO-NPs (1.13 L $\left.\mathrm{g}^{-1}\right)>$ R-CuO-NPs $\left(0.88 \mathrm{~L} \mathrm{~g}^{-1}\right)>\mathrm{M}$-CuO-NPs $\left(0.34 \mathrm{~L} \mathrm{~g}^{-1}\right)$. Therefore the notable result was the highest removal efficiency and $\mathrm{K}_{d}$ value for the A-CuO-NPs which implies the considerable capacity of this synthesized nanoparticle for $\mathrm{Pb}$ adsorption in comparison with the other two synthesized nanoparticles. Nozohour Yazdi et al. [30] reported that $\mathrm{K}_{\mathrm{d}}$ value in the sorption of $\mathrm{Pb}\left(200 \mu \mathrm{g} \mathrm{L}^{-1}\right)$ onto a fabricated polysulfides as a novel adsorbent was $2.42 \mathrm{~L} \mathrm{~g}^{-1}$.

Sorption isotherms

Parameters derived from Langmuir and Freundlich isotherms in the sorption of $\mathrm{Pb}$ ions by three synthesized copper oxide nanoparticles are given in Table 2. The best fitted data to Langmuir and Freundlich were observed in the adsorption of $\mathrm{Pb}$ onto the M-CuO-NPs (with $\mathrm{R}^{2}$ values of 0.99 and 0.98 for Langmuir and Freundlich, respectively). For the M-CuO-NPs, Langmuir constant $\left(K_{\mathrm{L}}\right)$ was $0.06 \mathrm{~L} \mathrm{mg}^{-1}$. Monolayer surface adsorption (b) in Langmuir isotherm for the M-CuO-NPs was $50 \mathrm{mg} \mathrm{g}^{-1}$. The values of $\mathrm{K}_{\mathrm{F}}$ and $\mathrm{n}$ in Freundlich isotherm show that the adsorption capacity and sorption intensity in the M-CuO-

NPs were $4.7\left(\mathrm{mg} \mathrm{g}^{-1}\left(\mathrm{~L} \mathrm{mg}^{-1}\right)^{1 / \mathrm{n}}\right)$ and 1.15, respectively. The values of standard errors in Table 2 showed that Langmuir was a better model in comparison with Freundlich for the sorption of $\mathrm{Pb}$ by the synthesized nanoparticles. In addition, the best fitted belonged to the adsorption of $\mathrm{Pb}$ onto the M-CuONPs. General morphologies of the three green synthesized copper oxide nano particles were important factors to determine the sorption characteristics of $\mathrm{Pb}$ ions. The smooth configuration of the M-CuO-NPs in comparison with coarse shapes in the A-CuO-NPs and R-CuO-NPs (Fig 3) probably caused more uniform adsorption in the M-CuO-NPs than those of the other two studied copper oxide nanoparticles. Sorption characteristics of $\mathrm{Pb}$ by other adsorbents have been reported in many studies. Zhou et al. [31] reported that Langmuir and Freundlich parameters in the removal of $\mathrm{Pb}$ by chitosan-modified biochars were $14.3 \mathrm{mg} \mathrm{g}^{-1}, 0.3 \mathrm{~L} \mathrm{mg}^{-1}, 8.2\left(\mathrm{mg}^{(1-n)} \mathrm{Ln} \mathrm{g}^{-1}\right)$, and $0.12 \mathrm{for} b, \mathrm{~K}_{\mathrm{L}}, \mathrm{K}_{\mathrm{F}}$ and $\mathrm{n}$, respectively. Monolayer sorption capacity in the sorption of $\mathrm{Pb}$ onto green synthesized zinc oxide nanoparticles has been reported $15.65 \mathrm{mg} \mathrm{g}^{-1}$ by Azizi et al. [32].

The negative values of Gibb's free energy, presented in Table 3, show that the sorption processes of Pb by all three studied nanoparticles were the spontaneous reactions. The most and least spontaneity were observed in the adsorption of Pb onto the A-CuO-NPs (-15.74 kJmol $\left.{ }^{-1}\right)$ and M-CuO-NPs (-14.77 kJmol $\left.{ }^{-1}\right)$, respectively. Therefore the quantities of Gibb's free energy also confirm that the highest and lowest tendency for the adsorptions of $\mathrm{Pb}$ in the solution belonged to the A-CuO-NPs and M-CuO-NPs, respectively. Relation between removal efficiency and Gibb's free energy have been reported in other 
researches. Mousavi et al. [33] found that in the adsorption of $\mathrm{Pb}$ and $\mathrm{Ni}$ ions by titanium oxide magnetic nanoparticles, removal efficiencies were 90 and $70 \%$ for $\mathrm{Pb}$ and $\mathrm{Ni}$, respectively. Accordingly, Gibb's free energy quantities for adsorption of $\mathrm{Pb}$ and $\mathrm{Ni}$ at temperature of $318 \mathrm{~K}$ were -8.27 and $-4.71 \mathrm{~kJ} \mathrm{~mol}^{-1}$, respectively. It can be resulted that the negative quantities of Gibb's free energy and spontaneity in a sorption reaction increases with increasing the sorption strength of an adsorbent.

\section{Conclusion}

Results of present study showed that all three green synthesized copper oxide nanoparticles were efficient in the removal of $\mathrm{Pb}$ from aqueous solutions but their adsorption properties and morphologies were different. Comparison between the adsorption capacities of the three synthesized nanoparticles showed that the nanoparticles synthesized from astragalus leaf extract had the highest efficiency for the removal of $\mathrm{Pb}$ from aqueous solution. The sorption properties and morphology of the nanoparticles synthesized from rosemary were almost similar to those of synthesized from astragalus. The sorption strength in nanoparticles synthesized from rosemary was relatively lower than that of synthesized from astragalus. In comparison with rough morphology in copper oxide nanoparticles synthesized from astragalus and rosemary, the smooth configuration in the nanoparticles synthesized from mallow leaf extract caused lower removal efficiency in the nanoparticle synthesized from mallow as compared to those synthesized from astragalus and rosemary. Sorption of $\mathrm{Pb}$ onto the nanoparticles synthesized from mallow leaf extract was the best fitted to Langmuir and Freundlich isotherms. Despite the lowest removal efficiency, higher dry mass of nanoparticles could be obtained from mallow leaf extract. The patterns that emerges from the present study was the preparation of environmentally friendly nanoparticles efficient in lead removal using abundant plant covers and low-cost and easy preparation processes.

\section{Declarations}

\section{Acknowledgments}

The authors are grateful to the Department of Soil Science, School of Agriculture, Shiraz University, Shiraz, Iran.

\section{Authors' contributions}

The manuscript was based on a draft written through the contributions of $A Z$ and RGH. Both authors read and approved the final manuscript.

\section{Competing interests}

The authors declare that they have no competing interests.

\section{Availability of data and materials}


The datasets used and/or analyzed during the current study are available from the corresponding author on reasonable request.

\section{Funding}

This work was supported by the Ministry of Science and Technology of Iran, Shiraz University.

\section{References}

1. El-Alfy MA, Hasballah AF, El-Hamid HTA, El-Zeiny AM. Toxicity assessment of heavy metals and organochlorine pesticides in freshwater and marine environments, Rosetta area, Egypt using multiple approaches. Sustain Environ Res. (2019); 29:19.

2. He Y, Wu P, Xiao W, Li G, Yi J, He Y, Chen C, Ding P, Duan Y. Efficient removal of $\mathrm{Pb}(\mathrm{II})$ from aqueous solution by a novel ion imprinted magnetic biosorbent: Adsorption kinetics and mechanisms. PLOS ONE. 2019;14(3): e0213377.

3. Alghamdi AA, Al-Odayni AB, Saeed WS, Al-Kahtani A, Alharthi FA, Aouak T. Efficient adsorption of lead (II) from aqueous phase solutions using polypyrrole-based activated carbon. Mater. 2019;12:2020.

4. Ojeme VC, Ayodele O, Oluwasina OO, Okoronkwo EA. Adsorption of $\mathrm{Pb}(\mathrm{II})$ ions from aqueous solutions using chemically treated and untreated cow dung ash. Bio Res. 2019;14(2):2622-2641.

5. Arbabi M, Hemati S, Amiri M. Removal of lead ions from industrial wastewater: A review of Removal methods. Int J Epidem Res. 2015;2(2):105-109.

6. Singanan M, Abebaw A, Vinodhini S. Removal of lead ions from industrial waste water by using biomaterials: A novel method. Bull Chem Soc Ethiop. 2005;19(2):289-94.

7. Li X, Li H, Xu X, Guo N, Yuan L, Yu H. Preparation of a reduced graphene oxide@stainless steel net electrode and its application of electrochemical removal pb(ii). J Electrochem Soc. 2017;164:E71E77.

8. Naushad M, Ahamad T, Sharma G, Al-Muhtaseb AH, Albadarin AB, Alam MM, ALOthman ZA, Alshehri $\mathrm{SM}, \mathrm{Ghfar}$ AA. Synthesis and characterization of a new starch/SnO2 nanocomposite for efficient adsorption of toxic Hg2 metal ion. Chem Eng J. 2016;300, 306e316.

9. Kavak D. Removal of lead from aqueous solutions by precipitation statistical analysis and modeling. Desalin Water Treat. 2013;51:1720-1726.

10. Gao J, Sun SP, Zhu WP, Chung TS. Chelating polymer modified P84 nanofiltration (NF) hollow fiber membranes for high efficient heavy metal removal. Water Res. 2014;63: 252e261.

11. Lin Z, Weng X, Owens G, Chen Z. Simultaneous removal of $P b(I I)$ and rifampicin from wastewater by iron nanoparticles synthesized by a tea extract. J Clean Prod. 2020;242:118476.

12. Mondal S. Potential of nanotechnology for rural applications. Arab J Sci Eng. 2020;45:5011-5042.

13. Farghali $\mathrm{AA}$, Bahgat $\mathrm{M}$, Enaiet Allah $\mathrm{A}$, Khedr $\mathrm{MH}$. Adsorption of $\mathrm{Pb}(\mathrm{II})$ ions from aqueous solutions using copper oxide nanostructures. Beni-Suef Univ J Basic and Appl Sci. 2013;2:61-71. 
14. Din MI, Rehan R. Synthesis, characterization, and applications of copper nanoparticles. Anal Lett. 2017;50(1):50-62.

15. Gawande MB, Goswami A, Felpin FX, Asefa T, Huang X, Silva R, Zou X, Zboril R, Varma RS. Cu and Cu-Based nanoparticles: synthesis and applications in catalysis. Chem Rev. 2016;116 (6):3722-3811.

16. Iravani S. Green synthesis of metal nanoparticles using plants. Green Chem. 2011;13:2638.

17. Menon S, Agarwal H, Shanmugam VK. Catalytical degradation of industrial dyes using biosynthesized selenium nanoparticles and evaluating its antimicrobial activities. Sustain Environ Res. 2021;31:2.

18. Kuppusamy P, Ilavenil S, Srigopalram S, Maniam GP, Yusoff MM, Govindan N, Choi KC. Treating of palm oil mill effluent using Commelina nudiflora mediated copper nanoparticles as a novel biocontrol agent. J Clean Prod. Just accepted manuscript. 2017. doi: 10.1016/j.jclepro.2016.09.176.

19. Sankar R, Manikandan P, Malarvizhi V, Fathima T, Shivashangari KS, Ravikumar V. Spectrochim Acta Part A: Mol Biomol Spectros. 2014;121:746-750.

20. Contreras S, Henríquez-Vargas L, Álvarez PI. Arsenic transport and adsorption modeling in columns using a copper nanoparticles composite. J Water Proc Eng. 2017;19:212-219.

21. Hamzaoui $M$, Bestani $B$, Benderdouche $N$. The use of linear and nonlinear methods for adsorption isotherm optimization of basic green 4-dye onto sawdust-based activated carbon. J Mater Environ Sci. 2018;9(4):1110-1118.

22. Sikdar D, Goswami S, Das P. Activated carbonaceous materials from tea waste and its removal capacity of indigo carmine present in solution: synthesis, batch and optimization study. Sustain Environ Res. 2020;30:30.

23. Issaabadi Z, Nasrollahzadeh M, Sajadi SM. Green synthesis of the copper nanoparticles supported on bentonite and investigation of its catalytic activity. J Clean Prod. Just accepted manuscript. 2016. doi: 10.1016/j.jclepro.2016.10.109.

24. Thekkae Padil VV, Černík M. Green synthesis of copper oxide nanoparticles using gum karaya as a biotemplate and their antibacterial application. Int J Nanomed. 2013;8:889-98.

25. Pavia DL, Lampman GM, Kriz GS, Vyvyan JR. Introduction to spectroscopy. Department of Chemistry Western Washington University Bellingham, Washington. Fifth edition. Chapter 2. 2013. pp. 14-106.

26. Singh S, Kumar N, Kumar M, Jyoti, Agarwal A, Mizaikoff B. Electrochemical sensing and remediation of 4-nitrophenol using bio-synthesized copper oxide nanoparticles. Chem Eng J. 2017;313:283-292.

27. Daryabeigi Zand A, Rabiee Abyaneh M. Adsorption of lead, manganese, and copper onto biochar in landfill leachate: implication of non-linear regression analysis. Sustain Environ Res. 2020;30(1):1-16.

28. Ablouh E, Hanani Z, Eladlani N, Rhazi M, Taourirte M. Chitosan microspheres/sodium alginate hybrid beads: an efficient green adsorbent for heavy metals removal from aqueous solutions. Sustain Environ Res. 2019;29:5.

29. Ibupoto AS, Qureshi UA, Arain M, Ahmed F, Khatri Z, Brohi RZ, Kim IS, Ibupoto Z. ZnO/Carbon nanofibers for efficient adsorption of lead from aqueous solutions. Environ Technol. 
2020;41(21):2731-2741.

30. Nozohour Yazdi M, Yamini Y, Asiabi H, Alizadeh A. A metal organic framework prepared from benzene-1,3,5-tricarboxylic acid and copper(II), and functionalized with various polysulfides as a sorbent for selective sorption of trace amounts of heavy metal ions. Microchim Acta. 2018;185(11):525.

31. Zhou Y, Gao B, Zimmerman AR, Fang J, Sun Y, Cao X. Sorption of heavy metals on chitosan-modified biochars and its biological effects. Chem Eng J. 2013;231:512-518.

32. Azizi S, Mahdavi Shahri M, Rosfarizan M. Green synthesis of zinc oxide nanoparticles for enhanced adsorption of lead ions from aqueous solutions: equilibrium, kinetic and thermodynamic studies. Mol. 2017;22(6):831.

33. Mousavi SV, Bozorgian A, Mokhtari N, Gabris MA, Rashidi Nodeh H, Ibrahim WAW. A novel cyanopropylsilane-functionalized titanium oxide magnetic nanoparticle for the adsorption of nickel and lead ions from industrial wastewater: Equilibrium, kinetic and thermodynamic studies. Microchem J. 2019;145:914-920.

\section{Tables}

Table 1 Equilibrium concentrations of $\mathrm{Pb}$ after 24 hours agitation of three synthesized copper oxide nanoparticles in aqueous solutions $\left(\mathrm{C}_{\mathrm{e}}\right)$ with different initial concentrations $\left(\mathrm{C}_{0}\right)$.

\begin{tabular}{ccccccc}
\hline & $\mathrm{C}_{0}(\mathrm{mM})$ & 0.15 & 0.3 & 0.6 & 1 & 1.5 \\
\hline A-CuO-NPs & $\mathrm{C}_{\mathrm{e}}(\mathrm{mM})$ & 0.013 & 0.106 & 0.221 & 0.217 & 0.174 \\
R-CuO-NPs & $\mathrm{C}_{\mathrm{e}}(\mathrm{mM})$ & 0.016 & 0.108 & 0.241 & 0.278 & 0.226 \\
M-CuO-NPs & $\mathrm{C}_{\mathrm{e}}(\mathrm{mM})$ & 0.019 & 0.103 & 0.217 & 0.311 & 0.455 \\
\hline
\end{tabular}

A-CuO-NPs, R-CuO-NPs and M-CuO-NPs show copper oxide nanoparticles synthesized from astragalus, rosemary and mallow leaf extracts, respectively. Each figure is mean of two replications. 
Table 2 Isotherm parameters for the adsorption of $\mathrm{Pb}$ ions onto three synthesized copper oxide nanoparticles.

\begin{tabular}{llccc}
\hline Isotherms & Parameters & \multicolumn{3}{c}{ Copper oxide nanostructures } \\
\cline { 3 - 4 } & & A-CuO-NPs & R-CuO-NPs & M-CuO-NPs \\
\hline Langmuir & $\mathrm{b}\left(\mathrm{mg} \mathrm{g}^{-1}\right)$ & 17.24 & 30.3 & 0.06 \\
& $\mathrm{~K}_{\mathrm{L}}\left(\mathrm{L} \mathrm{mg}^{-1}\right)$ & 0.27 & 0.14 & 0.99 \\
& $\mathrm{R}^{2}$ & 0.66 & 0.76 & 0.05 \\
& $\mathrm{SE}$ & 0.05 & 0.05 & 4.7 \\
\hline Freundlich & $\mathrm{K}_{\mathrm{F}}\left(\mathrm{mg} \mathrm{g}^{-1}\left(\mathrm{mg}^{-1}\right)^{1 / \mathrm{n}}\right)$ & 18.54 & 15.64 & 1.15 \\
& $\mathrm{n}$ & 4.25 & 2.85 & 0.98
\end{tabular}

A-CuO-NPs, R-CuO-NPs and M-CuO-NPs show copper oxide nanoparticles synthesized from astragalus, rosemary and mallow leaf extracts, respectively. SE: Standard error.

Table 3 The quantities of Gibb's free energy $\left(\mathrm{kJmol}^{-1}\right)$ at $25{ }^{\circ} \mathrm{C}(298 \mathrm{~K})$ in the sorption of $\mathrm{Pb}$ onto three synthesized copper oxide nanoparticles on average in five concentrations of $\mathrm{C}_{0}(0.15$ to $1.5 \mathrm{mM})$.

\begin{tabular}{llll}
\hline Nanoparticle & A-CuO-NPs & R-CuO-NPs & M-CuO-NPs \\
\hline$\Delta G$ & -15.74 & -15.29 & -14.77 \\
\hline A-CuO-NPs, & R-CuO-NPs & and & M-CuO-NPs
\end{tabular}

A-CuO-NPs, R-CuO-NPs and M-CuO-NPs show copper oxide nanoparticles synthesized from astragalus, rosemary and mallow leaf extracts, respectively.

\section{Figures}




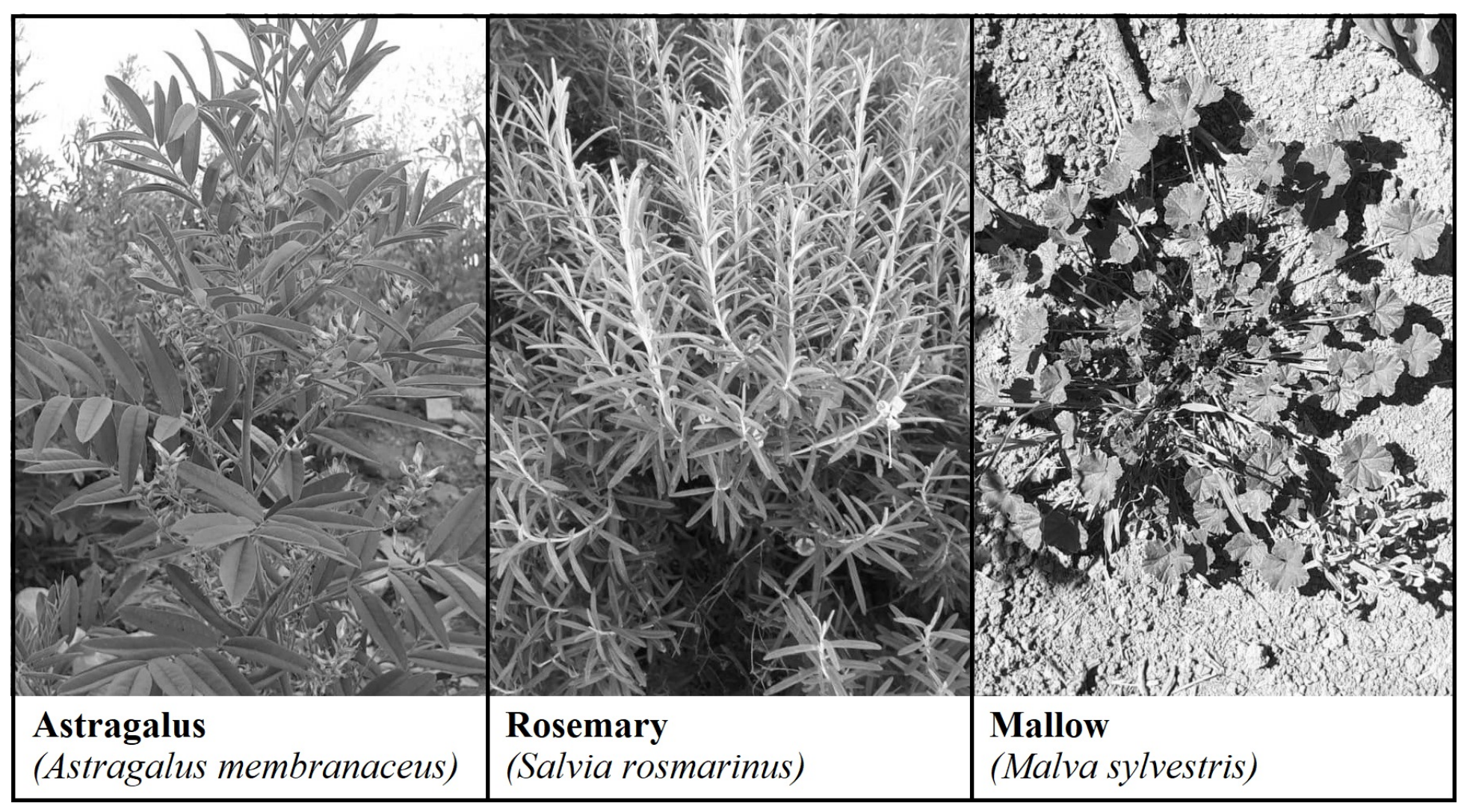

Figure 1

Selected plants from the study area used for green synthesis of copper oxide nanoparticles. 

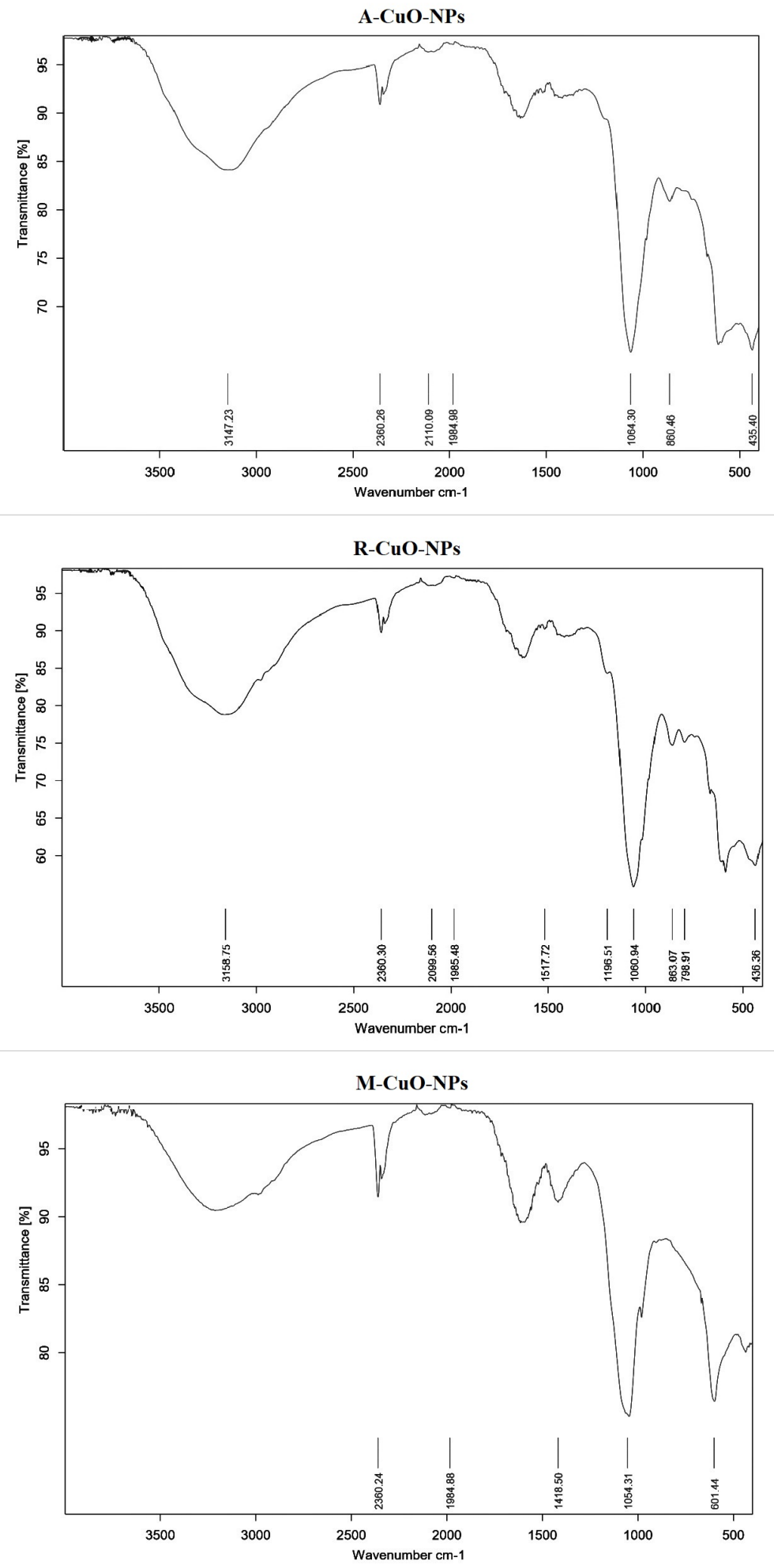

\section{Figure 2}

Infrared spectra of the studied copper oxide nanoparticles. A-CuO-NPs, R-CuO-NPs and M-CuO-NPs show copper oxide nanoparticles synthesized from astragalus, rosemary and mallow leaf extracts, respectively. 


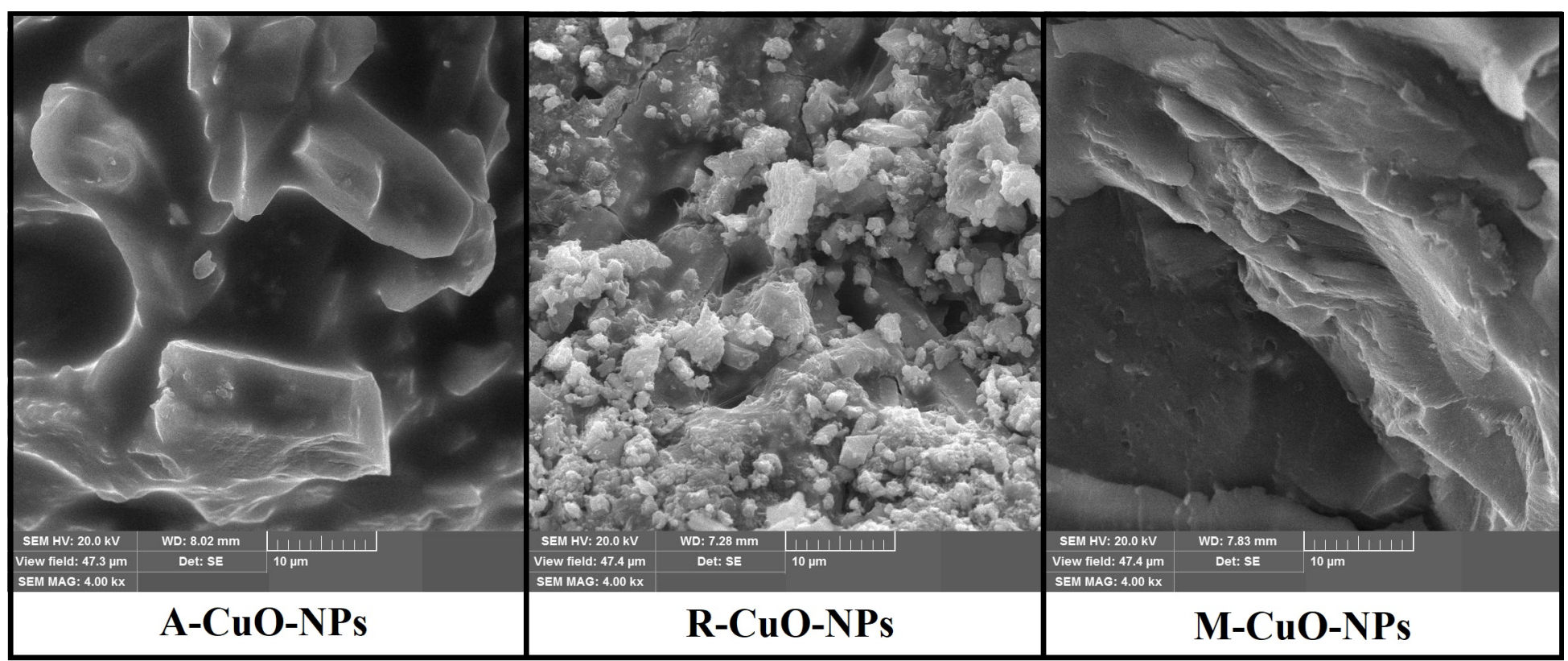

Figure 3

SEM micrographs of three studied copper oxide nanoparticles. A-CuO-NPs, R-CuO-NPs and M-CuO-NPs show copper oxide nanoparticles synthesized from astragalus, rosemary and mallow leaf extracts, respectively.

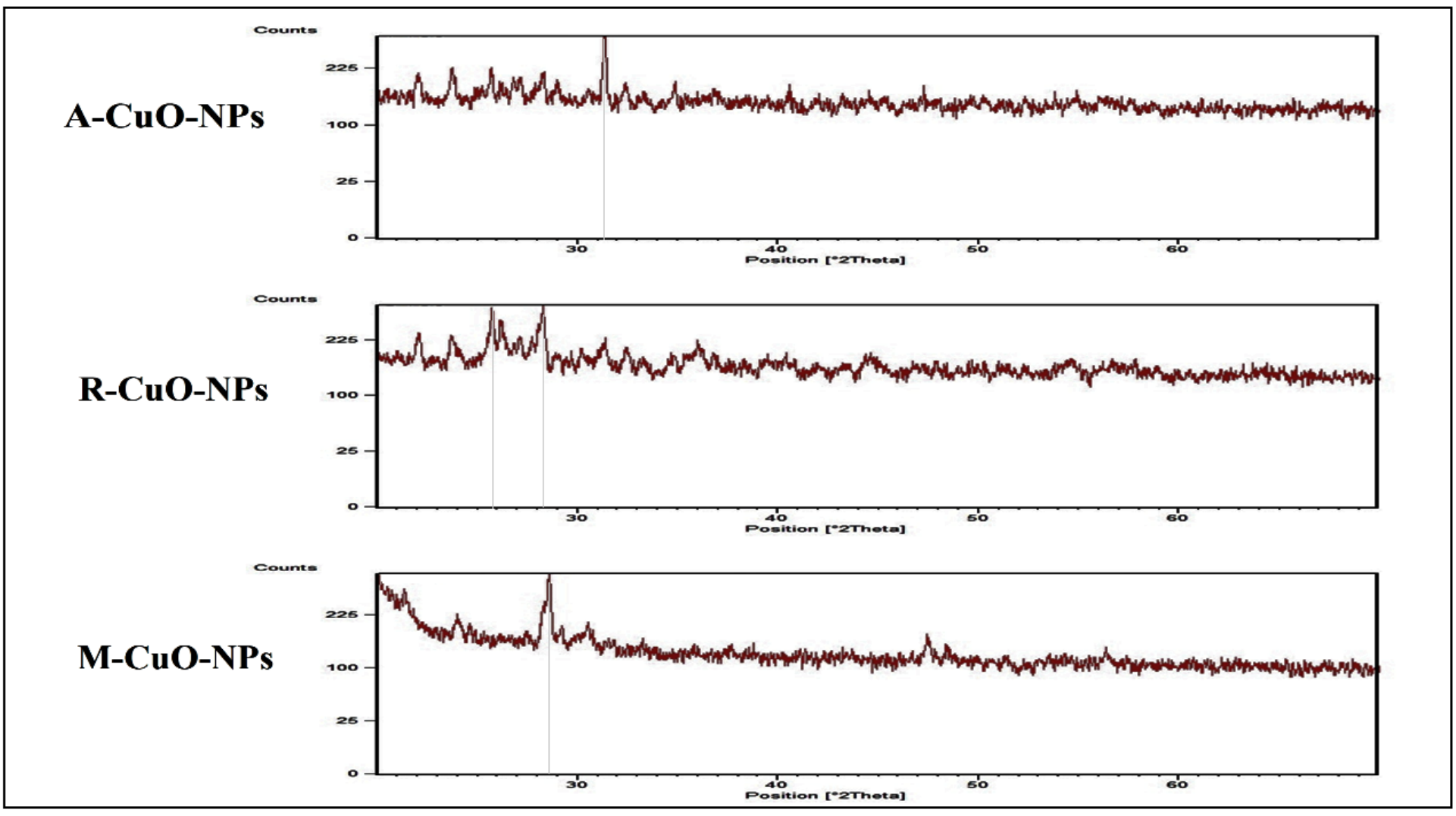

Figure 4 
XRD patterns of three green synthesized copper oxide nanoparticles. A-CuO-NPs, R-CuO-NPs and M-CuONPs show copper oxide nanoparticles synthesized from astragalus, rosemary and mallow leaf extracts, respectively.

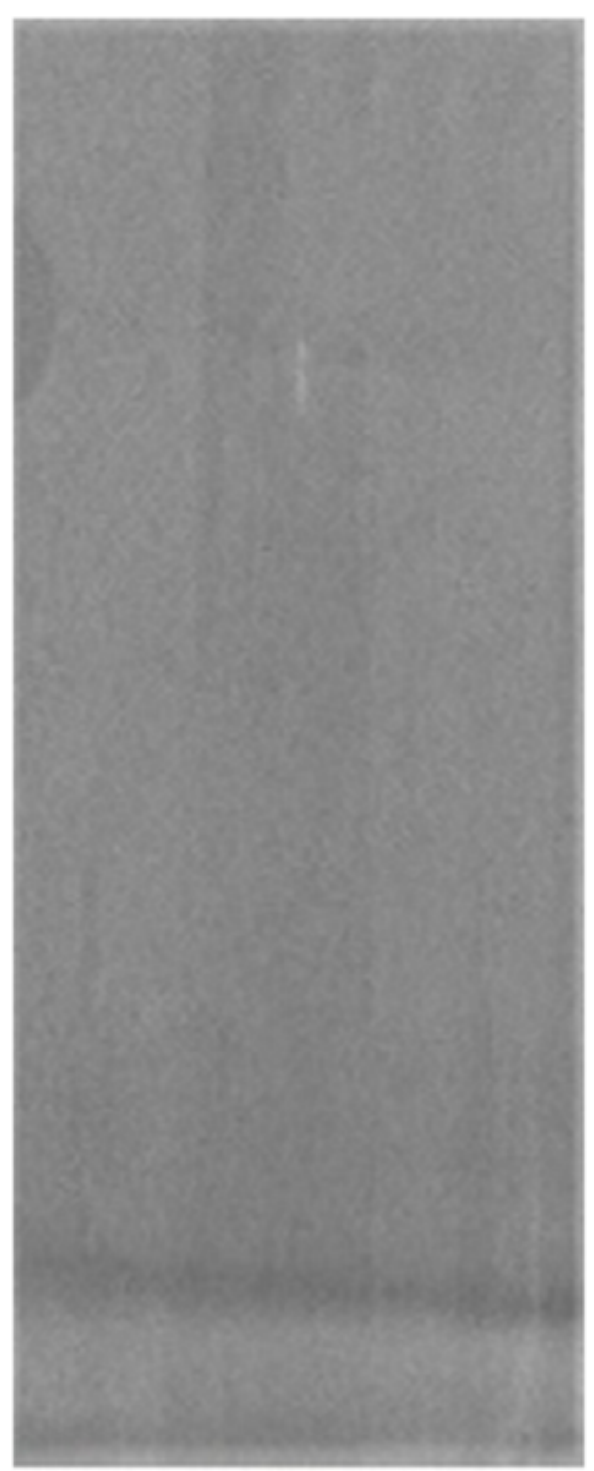

A-CuO-NPs

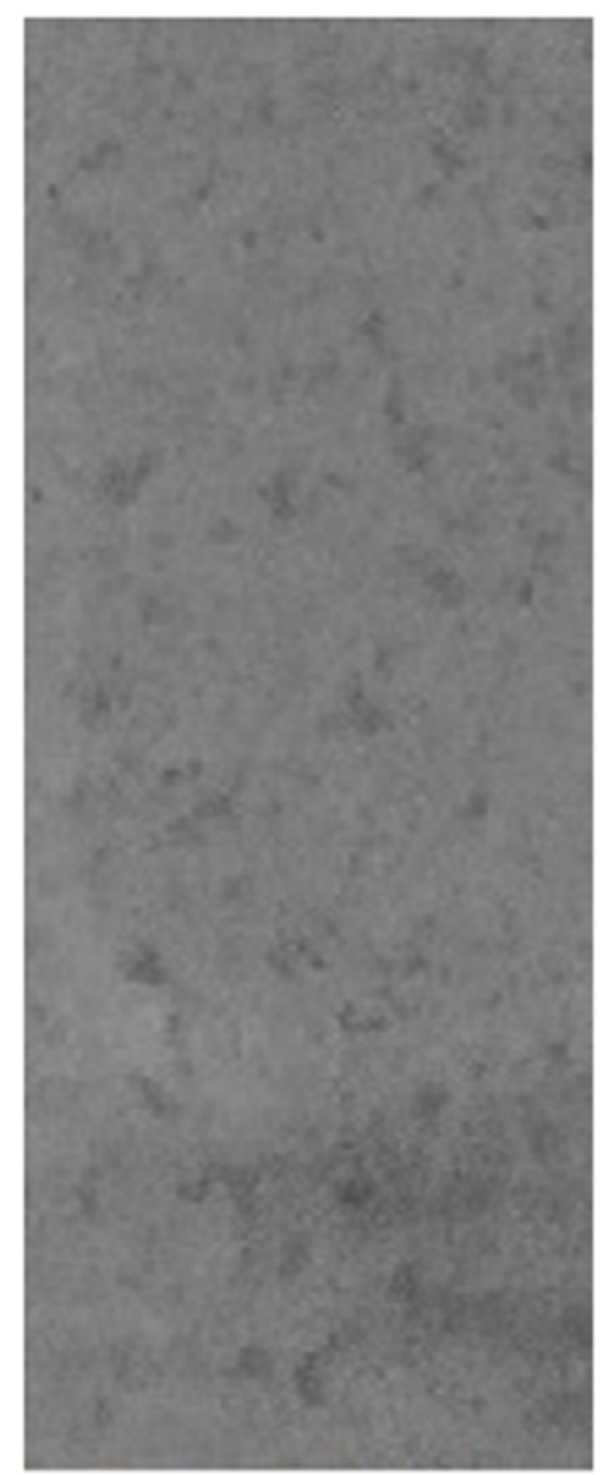

R-CuO-NPs

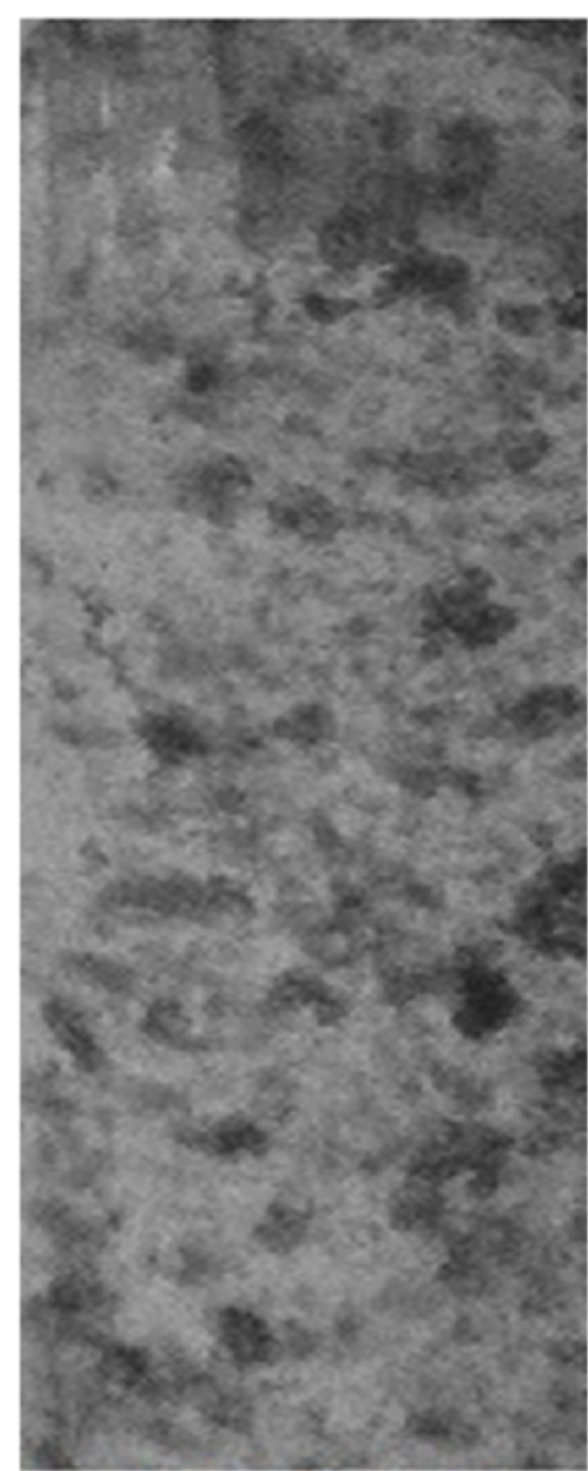

M-CuO-NPs

\section{Figure 5}

The close photos of the suspensions which represent the density of the synthesized copper oxide nanoparticles. A-CuO-NPs, R-CuO-NPs and M-CuO-NPs show copper oxide nanoparticles synthesized from astragalus, rosemary and mallow leaf extracts, respectively. 


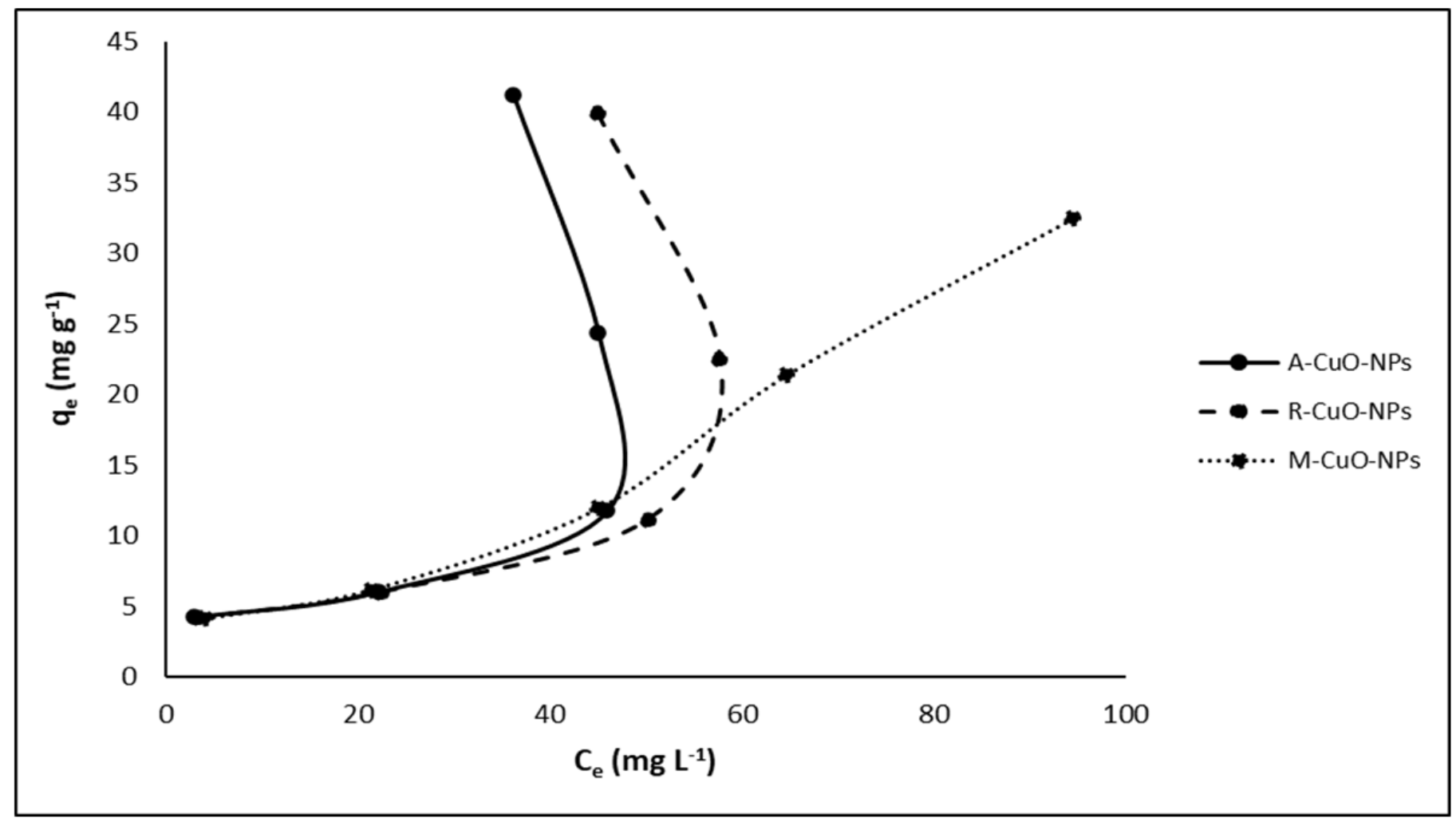

Figure 6

Relationships between equilibrium adsorption (qe) and equilibrium concentrations (Ce). A-CuO-NPs, RCuO-NPs and M-CuO-NPs show copper oxide nanoparticles synthesized from astragalus, rosemary and mallow leaf extracts, respectively. 